\title{
Assessing the Use of Cooking Demonstrations on Healthy Eating Barriers in City Bus Riders
}

\author{
Julianne Evans* \& Diana Cuy Castellanos \\ Department of Health and Sports Science, College of Education and Health Sciences, University of Dayton, OH \\ bttps:/ / doi.org/10.33697/ ajur.2019.017 \\ Student: evansj15@udayton.edu* \\ Mentor:dcuycastellanos1@udayton.edu
}

\begin{abstract}
People living in food-insecure households may experience access-related barriers to preparing and consuming fresh produce, such as high cost and limited local availability. Nutrition interventions that incorporate improved access play a decisive role in overcoming these barriers. The urban bus hub fresh produce market was developed to address food insecurity in Dayton, Ohio. Over four months, dietetic students from a four-year, private, mid-western university provided cooking demonstrations and recipe distribution nutrition interventions at the market. We used a quasi-experimental study design to determine the effectiveness of the cooking demonstration and recipe distribution intervention on access-related barriers at the urban bus hub fresh produce market. A ten-item quantitative questionnaire, on a Likert-type scale from 1-10, with 10 as a more favorable response, and four open-ended questions were administered once to each consented participant $(\mathrm{N}=33)$ to examine the recipe effectives and explore the access-related barriers. T-tests were used to examine barriers from the questionnaire and determine differences between participants who made the recipe and participants who did not make the recipe. Results of the t-test indicate no significant difference between those who made the recipe and those who did not make the recipe ( $\mathrm{p}>0.05)$. Mean scores for affordability, acceptability, accommodation, availability, and accessibility on the then ten-item questionnaire were 7.83, 8.44, 9.19, 9.38, and 8.44, respectively. Thematic analysis results were used to examine the barriers from the open-ended questions further and revealed that affordability and time barriers were present in the priority population. Lack of money, job loss, and unemployment were identified as contributing to affordability barriers and transportation and time to shop, prepare, or cook produce, and to find mealtimes were identified as contributing to time barriers. Nutrition professionals should continue developing appropriate interventions for affordability and time barriers in convenient locations for participants to encourage fruit and vegetable consumption and to establish evidence-based practices.
\end{abstract}

\section{KEYWORDS}

Cooking demonstrations; food insecurity; produce consumption barriers; nutrition intervention; food stand; recipe distribution; bus hub

\section{INTRODUCTION}

The definition of food security, as defined by the United States Department of Agriculture (USDA), is "access by all people at all times to enough food for an active, healthy lifestyle." ${ }^{1}$ Currently, concerning $11.8 \%$ of the nation reports some level of food insecurity, a household condition of uncertain or limited access to an adequate food supply. ${ }^{2}$ The state of Ohio has a food insecurity rate of $16.0 \%, 4.2 \%$ above the national average, with the city of Dayton at $18.0 \% .{ }^{2-4}$ Low socioeconomic status and low educational attainment often lead to food insecurity and may result in poor dietary behavior. ${ }^{5-8}$ Furthermore, food insecurity is a national concern due to its association with poor mental and physical health. ${ }^{5-8}$

Food insecurity is negatively associated with recommended fruit and vegetable intake, ${ }^{5-7}$ but positively related to unhealthy fat, refined sugar, and processed food intake, ${ }^{6-8}$ which may increase the risk for obesity. ${ }^{7}$ Addressing barriers related to consuming fruit and vegetables within food insecure populations could promote overall health. For instance, research indicates that fruit and vegetable consumption is associated with the ability to purchase and prepare fresh fruits and vegetables. ${ }^{5-8}$

Researchers have explored the barriers impacting fresh produce purchase, preparation, and consumption in low-income populations. The barriers relate to behaviors, attitudes, environments, education, and socioeconomic status. ${ }^{6-11}$ Environmental barriers include transportation, food cost, store locations, and hours of operation. ${ }^{9}$ Behavioral and attitudinal barriers include cooking skills, perception of time, discipline, lethargy, social values, norms, and consumer needs.7, 9-11 A few studies have connected these barriers into five access-related dimensions: availability, accessibility, affordability, accommodation, and acceptability. ${ }^{9-10}$ These five barriers were first identified by Penchansky and Thomas, as they identified a taxonomic definition for 
access as it related to healthcare systems and healthcare services. ${ }^{12}$ Caspi, Sorensen, Subramanian, and Kawachi were the first researchers to connect the five dimensions of access to the food environment and diet. ${ }^{10}$ Availability referred to locality and the supply of food, accessibility to transportation and travel time to get to the food supply, affordability to food cost, accommodation to consumer acceptance and adequacy to meet their needs, and acceptability to attitudes, including values and norms, towards the food supply. ${ }^{9-10}$ Nutrition interventions have been created, either directly or indirectly, to target the barriers associated with these five dimensions of access. $5,8,11,13-15$

Several studies assessed the impact of cooking classes and incentive programs at farmer's markets to help address barriers of affordability and acceptability. ${ }^{13-15}$ In one study, the farmer's market personnel provided a monetary incentive to help reduce produce cost and provided cooking classes to increase knowledge of fresh produce, self-efficacy, and healthy dietary behaviors. ${ }^{13}$ The focus groups and survey responses indicated the incentive program and cooking classes at the farmer's market increased fruit and vegetable consumption and positively changed their attitudes towards fruit and vegetables. ${ }^{13}$ Another study evaluated produce availability at markets and consumers knowledge of what was available through nutrition education. ${ }^{14}$ The nutrition education connected consumers, farmers, and food assistance program to evaluate the use of the fresh produce at the market. ${ }^{14}$ Availability, affordability, and accessibility barriers were also studied in senior citizen populations where they were provided with vouchers as farmer's sold their produce at established and new locations. ${ }^{14}$ Incentives and cooking classes or demonstrations are encouraging ways to increase fruit and vegetable consumption for low-income individuals by addressing the identified barriers, both environmental and behavioral. ${ }^{11,13-15}$ Furthermore, increased fruit and vegetable consumption, as a result of nutrition education paired with monetary incentives, is associated with reduced risk for food insecurity. 5,8

Another aspect of food access that is critical to understand is the concept of food deserts. A food desert is an area where there is inadequate access to healthy foods, such as fruits, vegetables, and whole grains. ${ }^{16}$ Food deserts contribute to the dimensions of access because it is a way to understand the accessibility dimensions, relating to travel and proximity of food supply. Dayton, Ohio is located within Montgomery County, where $66 \%$ of the food deserts in the county are located in the downtown area. ${ }^{17}$ Homefull, a local non-profit that addresses homelessness in the Dayton area, created a bus hub market to help address this accessibility barrier.

The market is a fresh fruit and vegetable stand located adjacent to the public transportation hub in downtown Dayton, Ohio. Homefull clients, who are part of a work entry program, oversee the market and the Homefull microfarm. ${ }^{18}$ Customers may pay for produce using Electronic Benefit Transfer (EBT), credit, or cash. In January of 2017, dietetics students from the University of Dayton began to implement weekly cooking demonstrations at the bus hub market to increase knowledge regarding fresh produce preparation, using culturally-appropriate recipes. Individuals at the bus hub could stop and watch the demonstration, sample food, speak with the students, and take a recipe card. The recipe card listed the ingredients, directions, nutrition facts, and describes health facts related to produce in the recipe. The primary researcher tailored the recipes for the priority population to be healthy, culturally appropriate, affordable, simple, and quick. The objective of this study was to assess the impact of cooking demonstrations on perceived barriers to fruit and vegetable preparation and consumption at the public transit hub produce market in downtown Dayton using quantitative and qualitative methods.

\section{METHODS AND PROCEDURES}

\section{Study Design}

This was a quasi-experimental study approved by the University of Dayton's Institutional Review Board.

\section{Participants}

The primary researcher recruited participants, using convenience sampling methods, during the cooking demonstrations at the bus hub market. Individuals who approached the cooking demonstration table took a recipe and were $\geq 18$ years old met the inclusion criteria.

\section{Setting}

The market has five to six food stands in a U-shape inside the bus hub. Centrally located is a check-out stand and on either side is one produce stand. There are 1-2 produce stands adjacent to these, making a U-shape. For the demonstrations that occurred once a week, the market manager would move the stands on the left side to create space for the portable sink and table. Additionally, one of the stands with a steel demonstration surface was used. Each surface was sanitized before use. Figure 1 indicates the set-up of the cooking demonstrations in the market. 


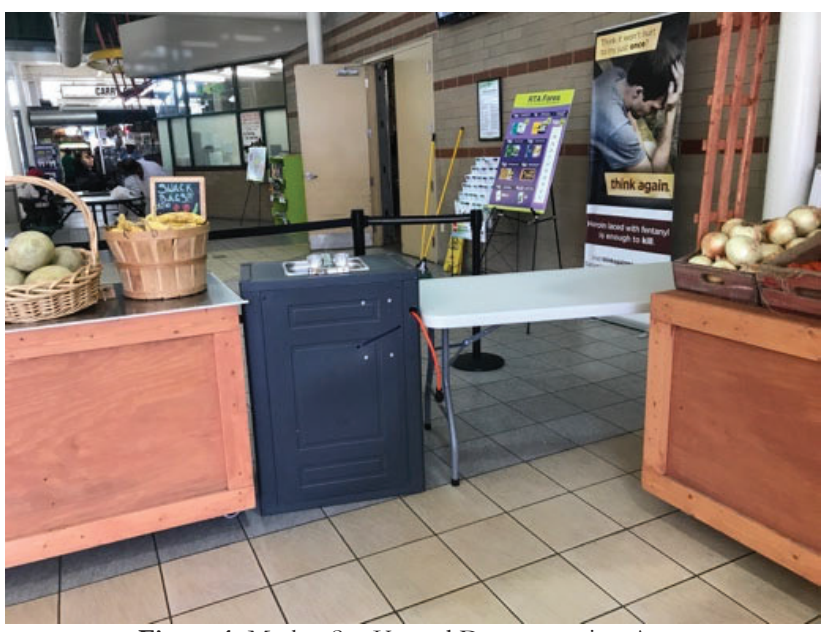

Figure 1. Market Set-Up and Demonstration Area.

Intervention Procedures

Cooking demonstrations occurred from August 2017 - February 2018, once a week in bus hub market. There was a total of 19 demonstrations and 19 recipes used. Demonstrations ranged from 1.5-2 hours, including set up and clean up time, depending on the recipe selected. The primary researcher selected a weekly recipe and performed the cooking demonstration with a trained dietetic student demonstrator, where recipe cards and samples were distributed. During the demonstrations, the dietetic students and primary researcher's engaged in casual conversation with individuals walking by or stopping to try the samples. The students and researchers would ask how people were doing and if they wanted to try the recipe. They might also answer any questions individuals had about the demonstration or recipe. Figure 2 is a sample of the distributed recipe cards to individuals walking in the bus hub. Figure 3 shows the various demonstrations and some of the recipes used in the intervention.

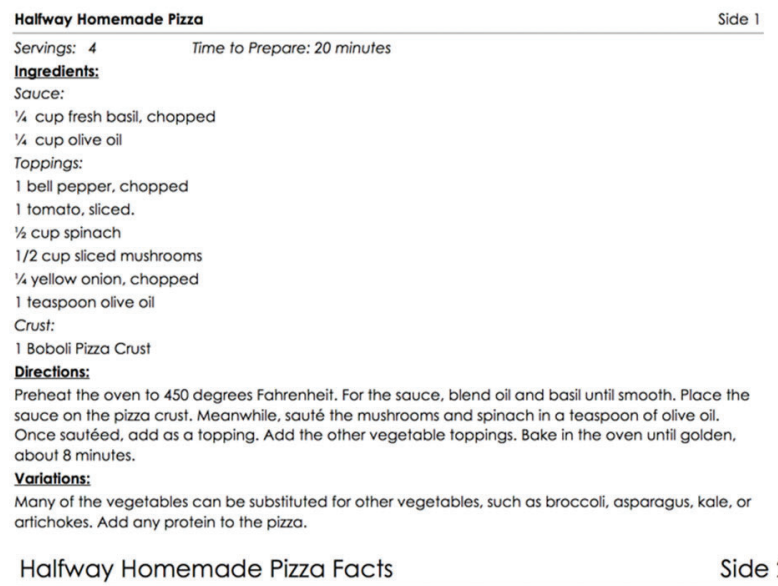

Halfway Homemade Pizza Facts

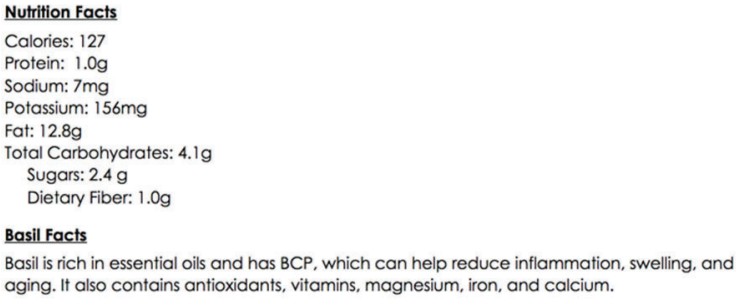

Figure 2. Recipe Card for Halfway Homemade Pizza. Side 1 has the recipe. Side 2 has the nutrition and food facts. 


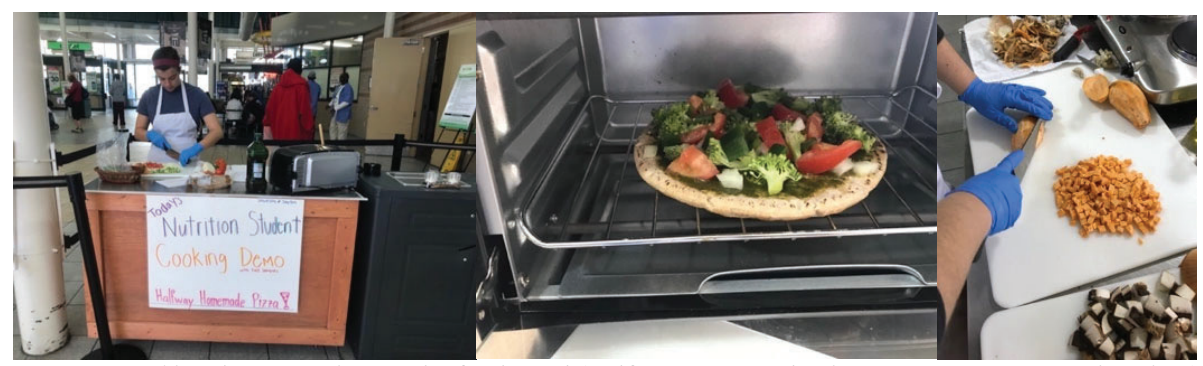

Figure 3. Cooking demonstrations at the food stand (Halfway Homemade Pizza \& Sweet Potato Hash recipes).

\section{Survey Procedures}

Survey collection occurred between August 2017 - February 2018. Through informal conversation with individuals in the bus hub about the demonstration, the primary investigator explained the research and asked if the individual would be willing to participate. If willing, the individuals signed a consent form and completed the best way to be contacted. Seven to ten days after the participant filled out the forms, the primary researcher telephoned the participant. When the participant answered the call, the primary researcher asked them questions from the questionnaire, including open-ended follow up questions.

\section{Data Instrumentation}

A questionnaire assessing the five identified barriers was adapted from a previous study examining fruit and vegetable purchase, preparation, and consumption barriers. ${ }^{9-10}$ The first item asked if participants made the recipe, which separated participants into the two groups of those who made the recipe and those who did not make the recipe. The remaining items were placed on a 1-10 Likert type scale, and participants indicated their degree of agreement with each statement, with 10 as most agreeable and 1 as least agreeable. Items 2-10 assessed the identified barriers and utilized adapted key terms listed in Table 1 to ascertain the degree of agreement.

\begin{tabular}{|l|l|l|}
\hline \multicolumn{1}{|c|}{ Item } & Barrier & Key Terms \\
\hline 2 & Affordability & Affordability of recipe \\
\hline 3 & Acceptability & Convenience of recipe \\
\hline 4 & Accommodation & Simplicity of recipe \\
\hline 5 & Affordability & Affordability of F/V \\
\hline 6 & Acceptability & Convenience of cooking F/V \\
\hline 7 & Accommodation & Simplicity of cooking F/V \\
\hline 8 & Availability & Location of market \\
\hline 9 & Accessibility & Hours market is open \\
\hline 10 & Acceptability & Knowledge of F/V preparation \\
\hline
\end{tabular}

Open-ended questions were created to gain a better understanding of the reasons participants did or did not prepare the recipe. For those who prepared the recipes, questions included describing the experience with making the recipe, such as time, recipe modification, where produce was purchased, what went well, and what did not go well. For those who did not prepare the recipes, the primary question asked was what prevented participants from making the recipe, and informal follow up questions about the barrier were asked.

\section{Statistical Analysis}

T-test, frequencies, and correlations were analyzed using IBM SPSS Ed. 23. Frequencies were calculated for gender and those who made the recipe vs. those who did not. Means and standard deviations for each of the five barriers and age were determined. $T$ tests were utilized to examine the mean difference between those who made the recipe versus those who did not make the recipe for each of the five barriers. Correlations were utilized to understand the relationship between recipe perception and fresh produce perception. Statistical significance was determined based on a $0.05 \alpha$ level. Thematic analysis was completed for the openended follow up questions. The access-related barrier definitions were used to identify themes in the participant responses. Keywords and phrases in the participant's responses were categorized based on which access-related barrier they spoke to provide a sense of their lived experience related to each of the barriers. 


\section{RESULTS}

Thirty-three participants completed the questionnaire, and the open-ended follow up questions. Of these participants, 21 were female, and 12 were male. The participant age range was between 20 and 66 years, with a mean age of 42.45 (SD = 14.87). Of the 33 participants, 17 made the recipe. Age and gender were collected; however, it was collected independently from the ten-item questionnaire and the four open-ended questions, so these variables could not be included in our analyses.

\section{T-Test Results}

Table 2 provides the average score for each of the five identified barriers, the t statistic, p-value, and eta-squared. Across the five categories for produce purchase, consumption, and preparation barriers, there was not a significant difference between those who made the recipes and those who did not make the recipes $(p>0.05)$. The mean score for the five barriers were all above 7.00 . Further, there was a minimal effect for each of the identified barriers.

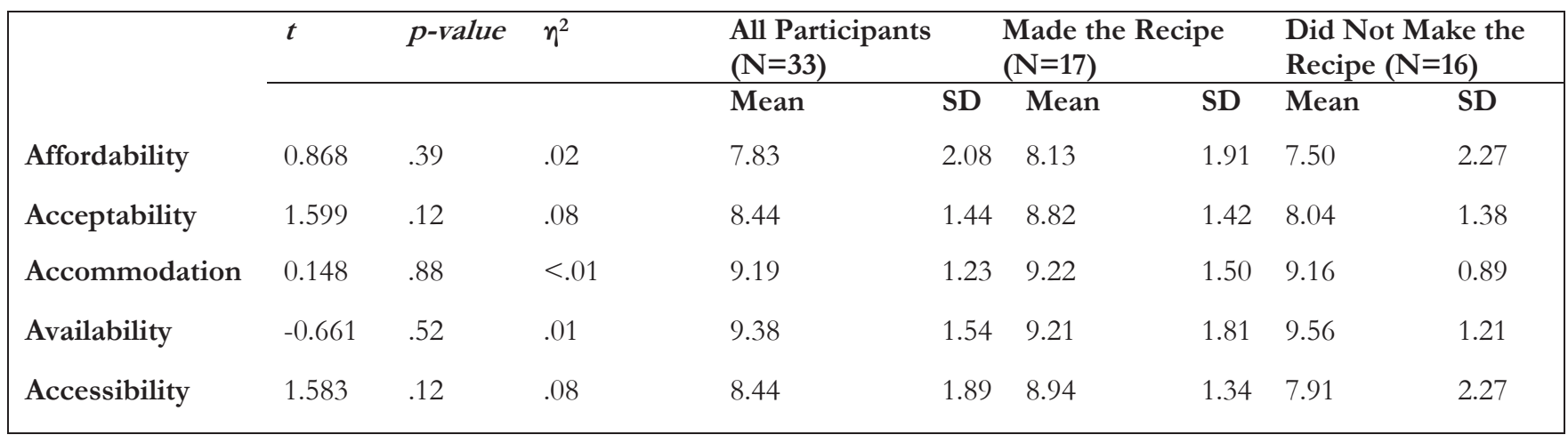

Table 2. Questionnaire Results Across Recipe Groups: mean, standard deviations, $t$-test, $p$-value, and eta-squared.

\section{Thematic Analysis Results}

The thematic analysis revealed detailed descriptions of the five identified barriers. Table 3 identifies key elements from the thematic analysis. One of the apparent barriers was affordability. Participants who made the recipe and participants who did not make the recipe indicated that it could be challenging to find the money to buy produce. Multiple factors for lack of money included low income, job loss, and unemployment. Additionally, grocery stores with competitive produce prices, such as Kroger, Aldi, and Save-A-Lot, contributed to variable produce affordability perception at the bus hub market because participants stated comparing produce prices at the Market to these grocers to find the "cheapest" produce possible.

\begin{tabular}{|c|c|c|}
\hline & Made the Recipe $(\mathbf{N}=17)$ & Did Not Make the Recipe $(\mathrm{N}=16)$ \\
\hline Affordability & $\begin{array}{l}\text { - Produce is more expensive in winter } \\
\text { - Comparing produce prices to find } \\
\text { the best deal }\end{array}$ & $\begin{array}{l}\text { - Lack of money to purchase produce (no } \\
\text { income or lack of money) } \\
\text { - Comparing produce prices to find the } \\
\text { best deal }\end{array}$ \\
\hline Acceptability & - $\quad$ Recipes were easy to follow & $\begin{array}{l}\text { - } \quad \text { Forgetting the recipe } \\
\text { - } \quad \text { Could not get the ingredients at the store }\end{array}$ \\
\hline Accommodation & $\begin{array}{l}\text { - } \quad \text { Recipes were helpful to have } \\
\text { - Easy to substitute recipes } \\
\text { ingredients with other produce } \\
\text { preferences }\end{array}$ & $\begin{array}{l}\text { - Lack of time due to work or medical } \\
\text { issues } \\
\text { Cannot cut/cook the produce in the } \\
\text { same way as performed during the } \\
\text { demonstration }\end{array}$ \\
\hline Availability & - $\quad$ Market is a good location & $\begin{array}{l}\text { - Market is not always close, but it is a } \\
\text { good location }\end{array}$ \\
\hline Accessibility & $\begin{array}{l}\text { - More open hours of operation } \\
\text { would be helpful }\end{array}$ & $\begin{array}{l}\text { - Lack of time to get to the hub due to a } \\
\text { job, traveling, or transportation }\end{array}$ \\
\hline
\end{tabular}

Table 3. Open-Ended Questions: Thematic Analysis Key Ideas 
Even more evident than affordability, the open-ended questions revealed that time was the most prominent barrier for those who did not make the recipe. Time prevented people from making the recipe. Time, as understood by participants, included time to find transportation to the store, shop for ingredients and produce, prepare and cook the recipe, and sit down and eat the prepared food. The barriers mentioned that required time and prevented people from making the recipe encompassed medical issues, job, travel, and transportation.

For those who made the recipe, key themes encompassed ideas on recipe simplicity and convenience, and self-efficacy of the participants. Although these did not appear to be barriers, participants mentioned that these factors helped them make the recipes on their own. Participants in this group also demonstrated a motivation to make the recipe by using phrases including a healthy lifestyle, eating more fruits and vegetables, healthy cooking, and concern for overall health.

\section{DISCUSSION}

Evaluating Barriers and the Nutrition Intervention

The purpose of the present study was to assess the impact of fresh produce cooking demonstrations and recipe distribution at an urban bus hub fresh produce market on the five identified barriers to recipe preparation and fruit and vegetable intake. Although there were no significant findings, understanding the impact of the null findings is essential for nutrition professionals. The null findings suggest the need for more evidence-based nutrition interventions for the priority population. The null findings differ from previous research, which suggests that similar target populations encounter the five identified barriers., 13, 15, 17, 19 The barriers found in previous research for low-income and food insecure populations include psychosocial, environmental, and educational barriers, encompassing the five barriers explored in this research..$^{5-9,13,15,17,19}$ Research indicates that addressing these barriers is vital for nutrition professionals. Studies have explored how nutrition professionals have the potential to address these barriers through gardening classes, cooking demonstrations paired with monetary incentives, and incentives paired with nutrition education. ${ }^{11,13-15}$ However, the findings from this research support the continual evaluation and re-assessment of nutrition interventions in less studied locations, such as programs in transportation hub markets, to begin developing more evidence for practice in these settings. Since food access related to transportation has been found to impact fruit and vegetable purchase and consumption, the need for interventions related to transportation might be valuable to nutrition professionals. ${ }^{1,9-11,17}$ Nutrition professionals can impact nutrition messages in these settings. $19,11,17$ This study provides a starting point for further research on nutrition interventions in unique settings.

Exploring the implications further, one common trend is the affordability barrier. Although not significant between the two groups studied, affordability had the lowest mean score across all five barriers. This is consistent with comments collected in the open-ended questions that reveal fresh produce purchase, preparation, and consumption is still largely dependent on the affordability of fresh produce. Since the cost was a central component of the thematic analysis and the lowest mean score, this demonstrates that affordability is still an important barrier to consider when understanding fresh produce perceptions and developing nutrition intervention, which is consistent with previous research.11, 14-15, 19 These studies indicate a positive relationship between monetary incentives, such as SNAP, Health Bucks, or another stipend, and perceptions of produce affordability and increased purchases and consumption of fruit and vegetables. ${ }^{11,14-15,19}$ Although the primary researcher could not directly address produce affordability by changing produce prices at the market or through incentives, the recipes were tailored to meet these needs. Ingredients were selected for their affordability, commonness in homes, and overall health quality. Additionally, the bus hub market coordinated by Homefull tried to address the affordability barrier by accepting EBT for fresh produce and offering reduced prices for some produce if it is bought in bulk amounts. Affordability of recipes is something that can be further explored in the development of nutrition interventions in settings where EBT and similar programs are already established.

In addition to the emphasis on affordability, the thematic analysis revealed that time was an important barrier for participants. Past research suggests that time is a more significant barrier when considering dietary behavior and meal preparation more so than monetary barriers, like the affordability of produce. ${ }^{20-24}$ One way time can be measured is through meal preparation time and labor cost. $^{20-24}$ Meal preparation includes items such as cooking or clean up time, while labor cost might include shopping or transportation. ${ }^{17-21}$ The labor cost and meal preparation time relates to healthy dietary behaviors because it helps to quantify the time and energy that goes into making a meal. ${ }^{20-24}$ Exploring the perception of time is an important result of this research because the null findings signify the importance of collecting more data on possible barriers this population encounters, one of the barriers being time. Furthermore, understanding time might be able to provide information on acceptability, accessibility, affordability, and accommodation barriers because they represent different aspects of labor cost. Acceptability and accommodation relate to labor cost because of their influence on dietary behaviors, including meal preparation, as related to consumer needs, values, and norms. ${ }^{9}, 20$ Accessibility and availability relate to time because of transportation and market location as part of the labor cost.9, ${ }^{20}$ The null findings of this research signify that barriers such as accessibility, availability, accommodation, and acceptability can be further explored as entities of time and labor cost that participants have. Participants 
perception of time can provide nutrition professionals with detailed information on how to overcome this barrier through effective and efficient nutrition interventions.

Another aspect to consider with null findings is that different aspects of the five barriers might already be addressed through the location of the produce market in the bus hub. The location of the market is convenient for people who use public transit, and it does not always require them to take another bus route to go to the grocery store. ${ }^{17}$ In this respect, the market is very accessible to people on the bus route. The market also accepts EBT, which could be addressing the barrier related to affordability. ${ }^{17}$ Furthermore, even the exposure to fresh produce could help reduce barriers related to acceptability, accommodation, and availability because just passing by a fresh produce market amidst other fast food options can alter social values and norms and the needs of individuals. Considering the barriers the market already addresses through their location, the null findings may indicate the market has been successful in addressing some the food insecurity issues in Dayton. ${ }^{16,17}$ The null findings may indicate that the five barriers have been addressed by the nutrition intervention, but more evidence would need to be collected to understand this possible relationship.

The cooking demonstration and recipe distribution nutrition intervention is an important aspect of continuing to address barriers to fresh produce purchase, preparation, and consumption, but the focus of the intervention should change based on the evidence from this study, indicating time as the most significant barrier the target population encounters. The null findings provide nutrition professionals with evidence that the intervention needs to change as the barriers people encounter with fresh produce purchase, preparation, and consumption change. Other researchers support the importance of continuing to disseminate nutrition information and provide education on cooking skills and produce preparation. ${ }^{7,9,11,13-15}$ Furthermore, this evidence is rooted in support from the dietetics practice that emphasizes the continual evaluation of programs as necessary for their development towards impact.

\section{Limitations}

The location of the market is in a Dayton food desert, and the market accepts EBT.14, 15 Although the study focused on food insecure individuals, we did not confirm that participants lived in a food-insecure household. Gender and age were collected, but they were independent of the questionnaire and thus could not be analyzed with the data because of the coding system used to keep participant information private. Furthermore, a sample size of 33 is another significant limitation because such a small sample is less representative of the population. These were all noteworthy limitations to participant demographics.

The Likert type scale used for the questions was broad (1-10), and participants might have benefited from small scale, which could have provided researchers with a more concise assessment of the five barriers. A pre-test and post-test could have also been used to assess the five barriers before and after the cooking demonstrations and recipe distribution. Lack of pre-testing and posttesting prevented the primary investigator from determining change and overall impact of the nutrition intervention because all participants watched the demonstrations and took the recipes. It is unclear if all participants made the recipes within a week after the demo or waited until a later date to make the recipes. In this way, the methodology limited the ability to assess the impact and outcome.

Similarly, a lack of consistency in the recipes used for the demonstrations may have reduced the ability to assess the impact and outcome. Since there were 19 different recipes for each of the 19 demonstrations, this might have created considerable variability in the ability of a participant to go home and make the recipe. Some recipes might have been easier to make at home for various reasons, contributing to varied accommodation and acceptability barriers based on the recipe. Recipes still might have also been more or less affordable, depending on what was being made. This variability in the recipes limited the ability to assess the effectiveness of the intervention. Additionally, the three dietetics students who assisted and led the cooking demonstrations with the primary researcher were all Caucasian females who built trust through the longevity of the positive interactions during the demonstrations. This trust could have contributed to some variability in responses, again, limiting the ability to assess impact.

More information on how time impacts implementing nutrition interventions and produce purchase, preparation, and consumption is essential, although it is a barrier not initially explored. ${ }^{16-20}$ A thorough understanding of participants perception on time could provide details on what drives people and prevents people from engaging with the demonstration and creating the recipes on their own.

\section{CONCLUSIONS}

It is important to continue developing nutrition interventions that can better meet the consumers' needs to increase fruit and vegetable preparation and consumption. As interventions are used at food stands and farmer's markets, it is important to continue to assess their impact on participants, evaluating how the interventions meet the consumers' needs, social values, norms, and how it increases fruit and vegetable preparation and consumption. The previous study of nutrition interventions in public transit hubs 
fresh produce markets is minimal and should continue developing. Information on the correlation between produce perception, transportation, and nutrition interventions can be further explored to help understand food insecurity and healthy lifestyles. This research serves as a pilot program for nutrition professionals to continue developing evidence-based practices on nutrition interventions at the public transit food stand, which are becoming frequent locations for nutrition education. Further ideas for this study include exploring labor cost and meal preparation time by interviewing people at the market on their perception of time-related barriers.

\section{ACKNOWLEDGMENTS}

The Stander Symposium Research Grant funded this study. We thank Homefull personnel, Dayton RTA personnel, dietetic students who administered the cooking demonstrations, and our participants for assisting in this study.

\section{REFERENCES}

1. Colemen-Jense, A, Gregory, A., \& Rabbitt, M. (2017) Overview: Food Security in the U.S., https:// mmw.ers.usda.gov/topics/foodnutrition-assistance/food-security-in-the-us/ (accessed Dec 2017)

2. Colemen-Jense, A, Gregory, A., \& Rabbitt, M. (2017) Key Statistics and Graphics, https://wmw.ers.usda.gov/topics/food-nutritionassistance/food-security-in-the-us/key-statistics-graphics/ (accessed Dec 2017)

3. Feeding America. (2015) Food Insecurity in Ohio, http:// map.feedingamerica.org/county/2015/overall/obio (accessed Dec 2017).

4. Feeding America. (2015) Food Insecurity in Montgomery County, bttp:/ / map.feedingamerica.org/county/2015/overall/obio/county/montgomery (accessed Dec 2017).

5. Savoie-Roskos, M., Druward, C., Jeweks, M., \& LeBlanc, H. (2016) Reducing food insecurity and improving fruit and vegetable intake among farmers' market incentive program participants, J Nutr Edu Behav 48.1, 70-76. bttps:// doi.org/10.1016/j.jneb.2015.10.003

6. Hampl, J., \& Hall, R. (2002) Dietetic approaches to US hunger and food insecurity, J Am Diet Assoc, 102.7, 19-923. https:/ / doi.org/ 10.1016/s0002-8223(02)90209-9

7. Rogers, B., Kegler, M.C., Berg, C. J., Haardorfer, R., \& Frederick G.T. (2016) Understanding the food insecurity and obesity relationship by examining potential mediators: an exploratory analysis, J Hunger Environ Nutr, 11.2, 195-209. https:// doi.org/10.1080/19320248.2015.1128863

8. Jablonski, B. B. R., McFadden, D. T., \& Colpaart, A. (2016) Analyzing the role of community and individual factors in food insecurity: identifying the diverse barriers across clustered community members. J Community Health, 41, $910-923$. bttps://doi.org/10.1007/s10900-016-0171-0

9. Wetherill, M. S., \& Gray, K. A. (2015) Farmers' markets and the local food environment: identifying perceived accessibility barriers for SNAP consumers receiving temporary assistance for needy families (TANF) in an urban Oklahoma community, $J$ Nutr Educ Behav 47.2, 127-33.e1. https:/ / doi.org/10.1016/j.jneb.2014.12.008

10. Capsi, C.E., Sorensen, G. Subramanian, S.V., \& Kawachi, I. (2012) The local food environment and diet: a systematic review, Health Place, 18.5, 1172-1187. https:// doi.org/10.1016/j. healthplace.2012.05.006

11. Eikenberry, N., \& Smith, C. (2004) Healthful eating: perceptions, motivations, barriers, and promoters in low-income Minnesota communities, J Am Diet Assoc, 104.7, 1158-1161. https:/ / doi.org/10.1016/j.jada.2004.04.023

12. Penchansky, R., \& Thomas, J.W. (1981) The concept of access; definition and relationship to consumer satisfaction. Med Care, 19.2, 127-140. https:// doi.org/10.1097/00005650-198102000-00001

13. Dannefer, R., Abrami, A., Rapoport, R., Sriphanlop, P., Sacks, R., \& Johns, M. (2015) A mixed-methods evaluation of a SNAP-ed farmers' market-based nutrition education program, J Nutr Educ Behav, 47.6, 516-525.e1. bttps:// doi.org/10.1016/j.jneb.2015.08.021

14. Caine-Bish, N., Vogliano, C., Gosky, A., \& Powell, E. (2013) Nutrition education at farmers market to increase produce consumption of consumers and clients of food assistance programs, J Nutr Educ Behav 45.4S, 22. bttps://doi.org/10.1016/j.jneb.2013.04.060

15. Kunkel, M. E., Luccia, B., \& Moore, A. C. (2003) Evaluation of the South Carolina seniors farmers' market nutrition education program." J Am Diet Assoc, 103.7, 880-883. https:// doi.org/10.1016/s0002-8223(03)00379-1

16. CDC (Centers for Disease Control and Prevention). (2017). Food desert. https:/ / www.cdc.gov/ healthcommunication/toolstemplates/entertainmented/ tips/FoodDesert.html (accessed Sep 2018).

17. Genth, C. (2017). West Dayton food access collective impact project in 2017 Montgomery County Food Summit: Harvesting Community Insights, Dayton, $\mathrm{OH}$, United States.

18. Homefull. (N.d.). Farm markets, http:// wmw.homefull.org/homefull-solutions/urban-agriculture-2/markets/(Accessed April 2019)

19. Payne, G. H., Wethington, H., Olsho, L., Jemigan, J., Farris, R., \& Walker, D.K. (2015) Implementing a farmers' market incentive program: Perspectives on the New York city health bucks program, Prev Chronic Dis, 10, 1-9.

bttps://doi.org/10.5888/pcd10.120285 
20. ERS (Economic Research Service). (2012) U.S household food security survey module: Three-stage design, with screeners, http://wmw.ers.usda.gov/datafiles/Food_Security_in_the_United_States/Food_Security_Survey_Modules/bh2012.pdf. (accessed Aug 2018)

21. Rose, D. (2007) Food stamps, the thrifty food plan, and meal preparation: the importance of the time dimension for US nutrition policy, J Nutr Educ Behav, 39.4, 226-232. bttps:/ / doi.org/10.1016/j.jneb.2007.04.180

22. Davis, G. \& You, W. (2010) The thrifty food plan is not thrifty when labor cost is considered, J Nutr, 140, $854-857$. https://doi.org/10.3945/jn.109.119594

23. Davis, G. \& You, W. (2011) Not enough money or not enough time to satisfy the thrifty food plan? A cost difference approach for estimating a money-time threshold, Food Policy, 36.2, 101-107. https:// doi.org/10.1016/j.foodpol.2010.09.001

24. Mancino, L. \& C. Newman. (2007) Who has time to cook? How family resources influence food preparation, bttps:/ / www.ers.usda.gov/webdocs/publications/45797/11722_err40_1_.pdf?v=0 (accessed Aug 2018)

\section{ABOUT STUDENT AUTHOR}

Julianne Evans is from Kettering, OH and graduated from The University of Dayton in May 2019, majoring in dietetics and minoring in sustainability, energy, and environment. Beginning in fall 2019, she is pursuing an M.S in Public Health Nutrition and a Dietetic Internship at The University of Tennessee, Knoxville.

\section{PRESS SUMMARY}

Lack of healthy food sources prevents food-insecure people from eating and creating meals with fresh produce. Barriers that play a key role in eating and cooking healthy are socioeconomic status, psychosocial behaviors, environmental factors, and educational attainment. Nutrition programs have positively impacted these barriers. Since previous research on nutrition programs has not been completed in public transportation hubs, the goal of this research was to determine the effectiveness of a cooking demonstration and recipe distribution program at a fresh produce market in an urban bus hub. People at the bus hub and the market could watch the demonstrations and take recipes. Participants who agreed to participate in the study were called and asked questions on barriers. After evaluating participants responses to these questions, researchers found that time is still a significant barrier that prevented people from creating meals with fresh produce. It is essential to keep developing and evaluating nutrition programs in convenient locations, such as public transit hubs, so that nutrition professionals can address barriers to eating and cooking healthy meals. 